tions on poetry and pedagogy, particularly since poetry offers a way of bridging the gap between composition on one side of Sullivan's divide and literature, theory, and creative writing on the other. Actually, it was construction work on this kind of bridge that led to my being asked to coordinate "On Poetry." For the past ten years I've convened a course called Reading, Teaching (and Enjoying) Poetry, in Middlebury College's Bread Loaf MA program. The course explores ways that the middle school and high school teachers enrolled in the program can combine poetry, creative body movement, and nonlinear writing projects with the composition work usually expected in English classes. Participants in the Bread Loaf course have come from rural schools in the Southeast as well as New England prep schools, from urban school districts like Newark and New Orleans as well as remote schools in the Navajo Nation. Teachers from the least privileged schools as well as from elite schools have reported the same results: approaching poetry in this way can free up students who are not good at "composition" and give them skills and confidence that turn out to be useful in more-traditional writing tasks. My attempt to put these ideas into action has been a succession of first-year core courses at Georgetown and the University of Southern California on poetry, body, and self.

No simple solution is going to make the divisions that Sullivan describes any easier to live with. Poetry, however, doesn't have to stay on the literaturetheory-creative-writing side of the divide.

Bruce R. Smith

University of Southern California

\section{Araki Yasusada: Authorship and Aesthetic Expression}

\section{TO THE EDITOR:}

I am writing in response to Eric R. J. Hayot's "The Strange Case of Araki Yasusada: Author, Object" (120 [2005]: 66-81). Since I am the editor and executor of Doubled Flowering: From the Notebooks of Araki Yasusada, I hope you will allow me to make an important clarification.

Overall, I think Hayot's essay is superb, one of the most original and complex discussions of
Yasusada to date: his fascinating consideration of the writing's "aesthetic relations to objects" (76) opens up a unique perspective on the work, and his close reading of two of the poems in Doubled Flowering adds up to an analytical tour de force, to say the least. All in all, it is a rich, challenging piece, and I am grateful, as the work's caretaker, for his terrific critical effort.

However, something Hayot asserts toward the opening of his essay is, I'm afraid, potentially misleading in a significant way. After summarizing a few of the many early responses to Doubled Flowering, he writes: "At the far end of these reactions stood Johnson, declaring that authorship itself is a kind of hoax, a trick played by bourgeois notions of property and propriety, the reverence for experience and witnessing being a symptom of a prelapsarian attitude toward the text as such" (68). The first point I wish to make is this: while it's true I have actively participated in the debate the work has provoked, and while I've also often remarked on the intriguing ways Tosa Motokiyu's Yasusada texts interface with theory and the politics of poetry, I have also often emphasized that Doubled Flowering was not primarily written as some kind of symbolic appeal for the "death of the Author" as against the "hoax" of conventional authorship or for any other poststructuralist notion. Ambiguities of agency, authenticity, ethnicity, and axiology inhabit the work, but these are, along with the ongoing critical commentaries branching out from them, largely incidental aftereffects to the original impetus of the fiction. Doubled Flowering, to be sure, prominently contravenes (inasmuch as it gestures toward alternative, more fluid stagings of poetic presentation) long-institutionalized protocols of authorial control and classification that dominate both "traditional" and "experimental" wings of our poetry. But its withdrawal of authorship (for Tosa Motokiyu, as Hayot explains, is the pseudonym of a writer, or writers, who did not wish to claim the work he, she, or they wrote) is rooted in felt ethical imperatives that are of a piece with the work's full aesthetic expression-imperatives that have little to do, again, with theoretical aforethought.

To say this is not to imply there was no self-reflexiveness or metacommentary that entered the work over the stages of its production, 
for there certainly was. The Yasusada does not pretend to be a pure, well-behaved archive, as it were, innocent, in its unfolding, of contamination and contradiction. But it originates, with all its fated failures, as an empathic expression and not as a punitive marshaling of theoretical polemic cloaked in the lambskin of poetry. That the simple effacement of an authorship from a book of openly imagined fragments about Hiroshima should have been so widely taken in the poetry world as that kind of punitive gesture is, in fact, one of the most interesting and poignant aspects of the writing's history.

The second point I wish to make is more straightforward and more crucial to me, as it would be to Motokiyu: the phrase at the end of the passage ("the reverence for experience and witnessing being a symptom of a prelapsarian attitude toward the text as such") gives the strong impression that the Yasusada corpus presumes to set itself above, and in judgment of, first-order testimonial literature-namely, poetry by those who witnessed, as victims, the bombings of Hiroshima and Nagasaki.

Nothing could be further from the truth. Doubled Flowering, if anything, stands as a kind of testimonial to the testimony of hibakusha literature-a view, incidentally, articulated by Hosea Hirata in an essay published last year by the National Institute of Japanese Literature (“Tsukurareta hibakusha shijin Araki Yasusada: Shi ni shinjitsu was hitsuyouka," Proceedings of the 27th International Conference on Japanese Literature [Tokyo, 2004] 155-167). Among the author's close relatives are survivors of Hiroshima, whose fragile testimony Hirata movingly recounts in an afterword he wrote for the forthcoming Also, with My Throat, I Shall Swallow Ten Thousand Swords: Araki Yasusada's Letters in English.

I want to be as clear as I can (insofar as I can) on this matter regarding Yasusada's relation to $h i$ bakusha literature, so please allow me to end with an answer I gave a few years back in an interview conducted by the editor of Atomic Ghost: Poets Respond to the Nuclear Age, the poet and critic John Bradley:

The Yasusada is most emphatically not motivated by an impulse to critique anything at all in hibakusha literature, nor does it pre- sume to set itself as an equal partner inside or alongside that body of work.... [Although it is inevitably a part of the broader realm of atomic bomb literature, it] exists in relation to hibakusha writing at a distance, as an afterimage or echo of it, if you will. And I would hold that Yasusada's apocryphal status makes that echo no less real. It whispers something about the doubled-fusing and mutuallydeformed flowering of our two cultures, about our unacknowledged confusion in each other, about some kind of deeper yearning to find our voices entwined with an otherness that we know has been inside of us always. All of which is pure speculation and fancy on my part, but I do feel strongly that the echo is authentic, and I think it has multiple frequencies.

(Interview, Readme,

ed. Gary Sullivan, 1999, 19 May 2004

$<$ http://home.jps.net/ nada/johnson.htm>)

I hope these comments help clarify the misleading moment in Hayot's otherwise brilliant study.

Kent Johnson

Highland Community College, IL

\section{Reply:}

I am grateful to Kent Johnson for his kind words regarding my essay on Araki Yasusada and for an opportunity to continue discussing the meaning and value of that strange archive. Johnson wishes to assure PMLA readers first that Doubled Flowering was not primarily motivated by a desire to stake claims in the authorial politics of the American poetry scene and second that the Yasusada project does not wish to set itself above hibakusha literature (which it would then see as hopelessly caught up in a belated theory of authorship) but rather is best understood as an attempt to echo that literature in another context-echoing here being a kind of hearing.

I regret writing a sentence that would give the impression that I disagree with either of those things; my sense of what the Yasusada project does is fairly close to Johnson's. Where it diverges, perhaps, has to do with the complex relation between Johnson and the project. I admit to referring occasionally to Johnson as the poems' author 